doi:10.1520/JTE20140507 / Vol.44 / No.6 / November 2016 / available online at www.astm.org

Manuscript received December 15, 2014 : accepted for publication August 17, 2015; published online December 14 2015.

${ }^{1}$ Dept. of Civil Engineering, Indian Inst. of Science, Bangalore, 560012, India (Corresponding author),

e-mail: rvsagar@civil.iisc.ernet.in

2 NGRI, Uppal, Hyderabad, 500007, India
R. Vidya Sagar ${ }^{1}$ and M. V. M. S. Rao ${ }^{2}$

\section{Acoustic Emission During Flexural Deformation of Reinforced Concrete Under Incremental Cyclic Loading}

\section{Reference}

Vidya Sagar, R. and Rao, M. V. M. S., "Acoustic Emission During Flexural Deformation of Reinforced Concrete Under Incremental Cyclic Loading," Journal of Testing and Evaluation, Vol. 44, No. 6, 2016, pp. 2182-2198, http://dx.doi.org/10.1520/JTE20140507. ISSN 0090-3973

\section{ABSTRACT}

Acoustic emissions ( $A E$ ) released during the flexure tests of reinforced concrete ( $R C$ ) beams under incremental cyclic loading conditions in the laboratory were subjected to improved $b$-value (Ib-value) analysis. Ib-value has been reported to be useful to detect, track, and investigate the various stages of micro-cracking and macro-crack damage in concrete. Further, $I b$-value has been found to be free from the influence of monitoring conditions. We observed in the present study that the $I b$-value began to decrease with the beginning of the formation of new micro-cracks, and then stabilized ( $\sim 1.0)$ and finally dropped down sharply to a very low value marking the onset of macro-crack damage and its growth in concrete. Additionally, when the $I b$-value decreased, AE with steep rise angle (RA) values were noticed with the formation and growth of micro-cracks in concrete. On the contrary, the average frequency (AF) of AE events was found to decrease during the micro- and macrocracking stages of the test beams. These experimental observations of AE-based $/ b$-value combined with RA and AF were useful for the detailed study of flexural deformation and the failure of concrete at various stages in the laboratory and, perhaps, in situ conditions as well.

\section{Keywords}

Acoustic emission, reinforced concrete, flexural deformation, $I b$-value, rise angle, damage

\section{Introduction}

In general, deformation of any structure under repeated cyclic loading is said to produce fatigue. Concrete structures, especially reinforced concrete (RC) bridges, invariably undergo repeated and incremental cyclic loading conditions during their service. Structural failure can occur in the RC 
structures at stress levels that are much lower than the yield strength [1-3]. Cement concrete is prone to have flaws resulting from hydration, shrinkage, etc. At the tip of these flaws, stresses begin to concentrate under force. As a result, new cracks can form and grow at the tip of these flaws, even when the applied normal stresses are low. When the crack length becomes critical and the material reaches maximum fracture toughness, the intact portion of an RC structure cannot sustain the applied load due to reduced stress resisting area [3].

Studies have been carried out on the cracking behavior of concrete under cyclic loading, and it is reported that progressive deterioration of the bond between coarse aggregate and cement matrix occurs under load. The overall deformation and failure is influenced by several parameters such as type of loading, range of loading, number of loading cycles, material properties, environmental conditions, etc. [4-21]. The mechanism of cracking in RC structures subjected to cyclic loading is still not satisfactorily well established, and numerous hypothesis related to crack initiation and propagation have been proposed [22-24].

In fact, during the fracture process in $\mathrm{RC}$ beams, concrete above the neutral axis is subjected to compressive stresses. Compressive failure due to cyclic loading in RC structures refers to compressive failure of concrete in the compression zone that is obvious in plain concrete. In general, higher-strength concrete tends to be more brittle and have a steeper post peak descent, that is, its post peak slope of force-deformation plot is steeper. However, in RC structures, because of the presence of steel, the curvature at the ultimate load depends on the extension (longitudinal strain) of steel reinforcement. If the RC structure is under-reinforced, the extension of steel reinforcement will be greater before concrete in the compression zone is first crushed and, therefore, relatively less brittle or more ductile. On the other side, there is no direct tensile failure of RC structures due to cyclic loading because of steel reinforcement unless the steel is extremely low in quantity. If the reinforcement steel is very low or, in other words, if it is highly under-reinforced, the steel may snap and brittle failure may occur.

Although quite a few theories and models are available to describe the progressive failure of concrete based on scalar parameters such as crack size and crack density, there is generally no single and widely accepted experimental technique. Researchers have found that the acoustic emissions (AE) monitoring technique is useful to study the damage evolution and fracture process in concrete at various scales in the laboratory as well as in situ. Researchers proposed methods to study crack propagation and crack classification in concrete using released $\mathrm{AE}$ based on the data of AE statistics, $b$-values, $I b$-values, rise time (RT), and average frequency (AF). The classification of cracks in concrete structures is performed using the relationship between $\mathrm{AF}$ and rise angle (RA) value. It was reported that shear crack occurred when the AE signal had high RA value and low AF, and tensile crack occurred when AE signal had low
RA value and high AF $[25,26]$. It was also concluded that classification of cracking using RA and AF values enables a warning against final failure. Ohno and Ohtsu stated that a greater RA value and a lower AF value indicates the onset of corrosion or rust-breakage of steel reinforcement [26]. When the RA value is low and the $\mathrm{AF}$ is high, it implies the occurrence of tensile crack due to corrosion. Ohno and Ohtsu investigated the fracture process in RC test specimen loaded under bending and observed using SiGMA analysis that AF and RA are useful for crack classification. RA and AF indices also have been explored for damage evaluation on cement-based materials [27].

\section{RELATION BETWEEN AE AND CRACK PROPAGATION DURING CONCRETE FRACTURE}

During the fracture process in quasi-brittle materials like concrete and rock, a number of AE events with different amplitudes are released due to micro-crack formation and growth in them at all scales $[3,27-32]$. The AE source location methods are useful in identifying and analyzing the various physical processes underlying the fracture in all engineering materials. Among the damage indices proposed, AE peak amplitudes are related directly to the scale of fracture [28-32]. Therefore, the scale of peak amplitude might be larger with the progress of fracture. AE-based $b$-value and $I b$-values are obtained from the $\mathrm{AE}$ amplitude distribution. The analysis of RA and the frequency content of $\mathrm{AE}$ are recent developments relatively in the usage of index parameters especially for concrete structures. Additionally, during the fracture process in RC structures, displacement and strain in steel and/or in concrete would also change. All these issues are addressed in this article.

\section{FREQUENCY-AMPLITUDE DISTRIBUTION RELATION}

$\mathrm{AE}$ amplitude data related to quasi-brittle materials is quite similar to the magnitude distribution data of earthquakes of a localized region [33-41]. The power-law distribution for earthquakes is as follows:

$$
\log _{10} N(>M) \propto-b M
$$

where:

$M=$ earthquake magnitude,

$N(>M)=$ the number of earthquakes with a magnitude larger than $M$, and

$b=$ the slope of the power law distribution of the numbermagnitude relationship of earthquakes $[33,34,37]$.

Since the earthquake magnitude $(M)$ is proportional to the log of the maximum amplitude (A) of the seismic signal, the $b$-values obtained from the amplitude data can be compared. In a semi-log representation, this power law size distribution appears linear and $b$ is given by the slope of the curve plotted using $N(>A)$ and $A[33,34,40]$. It is as follows:

$$
\log _{10} N(>A) \sim-b \log _{10} A
$$


Interestingly, this power law distribution of $\mathrm{AE}$ events related to quasi-brittle materials exhibits similarity to the GuttenbergRichter relationship observed for earthquakes. Generally, higher-magnitude earthquakes are small in number and lowmagnitude earthquakes occur in large numbers $[33,34,40]$. Analogous to the occurrence of earthquakes, during fracture process in RC structures, high-magnitude AE events occur less in number while the low-amplitude AE events released would be much large in number $[36,39,41]$.

In the context of $\mathrm{AE}$ monitoring technique, since the amplitude is measured in decibels $(\mathrm{dB})$, the Gutenberg-Richter formula is adopted as follows [36,39,41].

$$
\log _{10} N=a-b\left(\frac{A_{d B}}{20}\right)
$$

where:

$N=$ the number of AE hits (or events) with an amplitude higher than threshold $A_{d B}$,

$a=$ a constant determined largely by the background noise present in the surroundings of testing in a laboratory (or in situ), and

$b$ is the negative slope of the curve plotted between $\log _{10}(N)$ and the AE signal amplitude $\left(A_{d B}\right)$.

The $b$-value is the "log-linear slope of the frequencyamplitude distribution" of AE. In fact, the $b$-value represents the "scaling of amplitude distribution" of $\mathrm{AE}$ and is a measure of the relative numbers of small and large AE.

AE monitoring experiments on quasi-brittle materials such as concrete, rock, and ceramics are carried out mostly to monitor the formation and growth of micro-cracks from the beginning to the final failure of the test specimen and thereby to identify and track the critical state of micro-crack damage for several applications in materials research in structural engineering [42-47]. In other words, a relatively large number of AE events occurs with amplitudes at and around the threshold limit. This may be due to many sources other than micro-cracking during the fracture process in concrete.

$\mathrm{AE}$ can occur due to the closure of pre-existing cracks and voids, sliding on cracks, grain crushing, and other factors due to experimental conditions like loading rate, imperfect contacts between the test piece and platen, test specimen, and sensor, inadequate threshold setting, etc. All these give rise to several numbers of low-amplitude and short-duration AE, especially at and around the threshold value that is set. Thereby, the slope of the cumulative frequency-amplitude distribution plot(s) of AE is affected. In order to avoid or filter such low-amplitude, unwanted AE, researchers proposed $\mathrm{I} b$-value analysis, and it is a relatively new approach that is computed using recorded $\mathrm{AE}$ peak amplitude data $[27,39,40,48-50]$.

\section{Ib-VALUE ANALYSIS}

The $I b$-value is defined by utilizing statistical values of the AE amplitude distribution as mean and standard deviation and is given by the following equation:

$$
I b=\frac{\log _{10} N\left(w_{1}\right)-\log _{10} N\left(w_{2}\right)}{\left(\alpha_{1}+\alpha_{2}\right) \sigma}
$$

where:

$N\left(w_{1}\right)=$ the accumulated number of $\mathrm{AE}$ hits (or events) in which the amplitude is more than $\left(\mu-\alpha_{1} \sigma\right)$,

$N\left(w_{2}\right)=$ the accumulated number of $\mathrm{AE}$ hits in which the amplitude is more than $\left(\mu+\alpha_{2} \sigma\right)$,

$\sigma=$ the standard deviation of the amplitude distribution of a group of hits,

$\mu=$ the mean value of the amplitude distribution of the same group of hits, and

$\alpha_{1}$ and $\alpha_{2}=$ constants $[39,40,46-50]$.

Shiotani et al. studied the crack condition of an RC pier to damage quantification by using $I b$-value analysis and concluded that the $I b$-value can be used to assess damage [40,48-50].

In our previous study [51], we reported only the influence of loading rate on the precursory changes in $b$-value and strain in steel reinforcement and the assessment of micro-crack damage in concrete using such parameters. In the present study, we extended our work and carried out the $I b$-value analysis of $\mathrm{AE}$ and compared with the RA of the accompanying AE hits that are released during the flexural deformation and the fracture of RC beams. The mode of cracking and severity of damage in concrete at the laboratory scale using RA and $I b$-value have been discussed in detail.

\section{Aim of the Present Study}

Relatively, there is still a lack of sufficient experimental data concerning the effect of incremental cyclic loading on $\mathrm{AE}$ parameters related to RC structures, particularly the highway bridges subjected to incremental cyclic loading conditions. In this study, fracture processes in RC beam specimens at the laboratory scale are evaluated by applying the $I b$-value analysis. However, many concrete structures, such as highway bridges, are subjected to incremental cyclic forces. The fatigue strength and fracture behavior of concrete used in these structures is required for their safe, effective, and economical design. In the present study, authors have compared and analyzed the variations in $I b$ values with the rise angle and frequency characteristics of $\mathrm{AE}$ released during the incremental cyclic loading conditions of RC beams. 


\section{Experimental Procedures}

\section{MATERIALS AND TEST SPECIMENS}

All four test specimens were made up of the same concrete mix composition, and the 28-day compressive strength of concrete mix (maximum coarse aggregate size was $20 \mathrm{~mm}$ ) was $37 \mathrm{MPa}$. Each specimen was loaded at mid-span and was simply supported over a span $S$. The two-point loading span was $1 \mathrm{~m}$ with a 2.6 -m supporting span as shown in Fig. 1a. The geometry and reinforcement details are given in Table 1. In the same table, $\varnothing$ is the nominal diameter of reinforcement, $n$ is number of reinforcement bars; $A_{s}$ is area of reinforcement, $L$ is the beam length; $S$ is the span of the beam, $b$ is beam width, and $D$ is the beam depth.

\section{EXPERIMENTAL ARRANGEMENT}

The experimental setup consisted of a servo hydraulic loading frame $(1200 \mathrm{kN})$ with a data acquisition system and the $\mathrm{AE}$ monitoring system. A steel I-beam was placed beneath the actuator to transfer the force as two point forces. The force was applied (in four-point bending) in incremental cycles until failure of the specimen. The specimen was simply supported, and the generated $\mathrm{AE}$ signals were recorded using an eight-channel AE monitoring system. The data acquisition records force, displacement at the center of the beam, strain in the steel at the center of the RC beam, and time. The midspan displacement was measured using a linearly varying displacement transformer (LVDT), placed at the center on the underside of the RC beam as shown in Fig. 1a. The strain in the steel at the midsection of the test specimen was recorded using electrical resistant strain gauge $(120 \Omega)$ that was fixed to the main steel reinforcing bar (tensile reinforcement) before casting. An RC beam specimen in the test rig, structures lab, department of civil engineering, Indian Institute of Science (I.I.Sc.), Bangalore, India is shown in Fig. 1a and reinforcement details are shown in Fig. 1b.
FIG. 1

(a) RC beam test specimen (LLR2) instrumented with $\mathrm{AE}$ sensors for monitoring in the test rig, structures laboratory, Department of Civil

Engineering, Indian Institute of Science, Bangalore. (b) Reinforcement details in the RC beam. (c) Schematic diagram of the location of AE sensors.
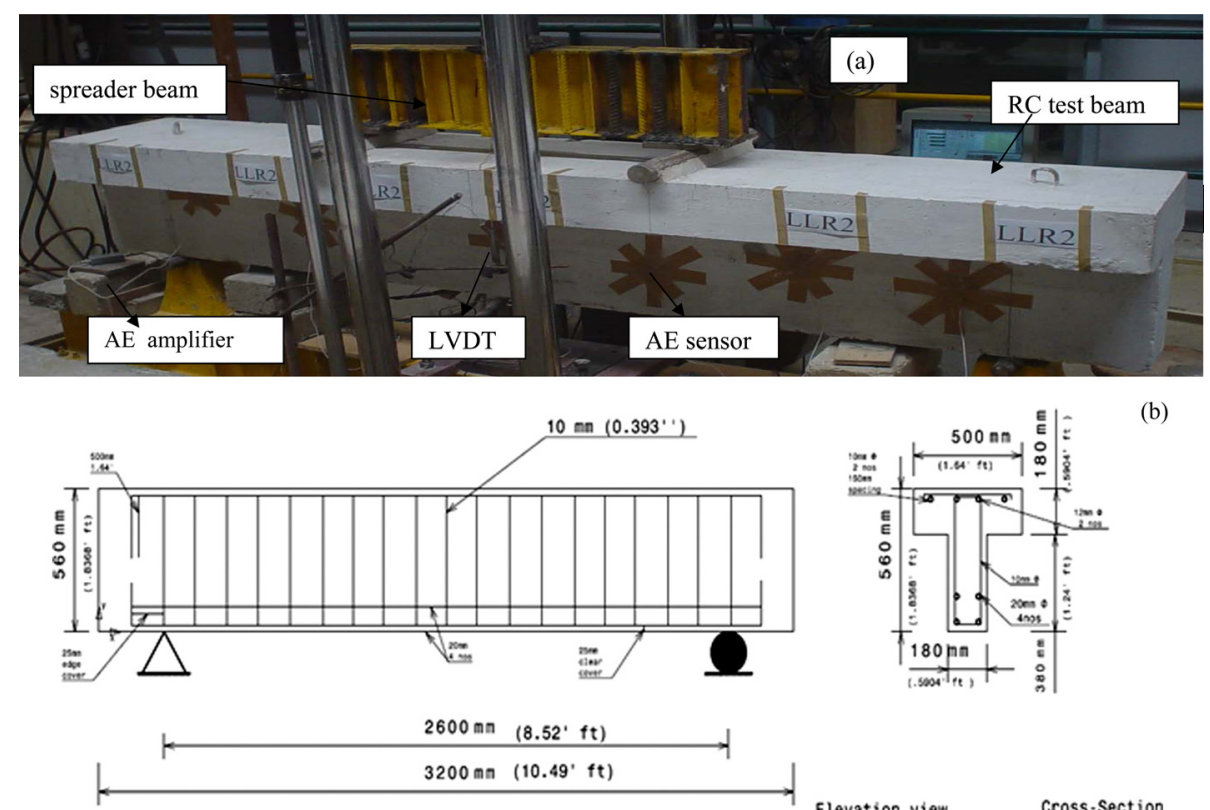

(b)

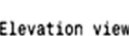
Scale: $1: 25$

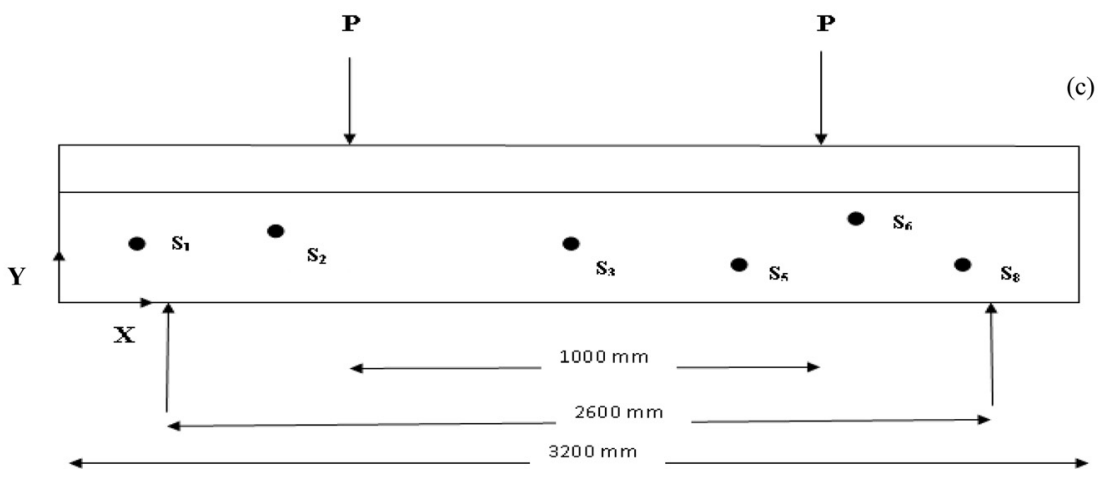


TABLE 1 Geometric details of RC test beams, rate of loading, and the $X$ and $Y$ coordinates of AE sensors.

\begin{tabular}{|c|c|c|c|c|c|c|c|c|c|c|c|c|c|c|c|c|c|c|c|c|c|c|c|c|}
\hline \multirow[b]{3}{*}{ Specimen } & \multirow[b]{3}{*}{$\begin{array}{c}\varnothing \\
(\mathrm{mm})\end{array}$} & \multirow{3}{*}{\multicolumn{2}{|c|}{$\begin{array}{c}A_{s} \\
\text { n }\left(\mathrm{mm}^{2}\right)\end{array}$}} & \multirow[b]{3}{*}{$\begin{array}{c}S \\
(\mathrm{~mm})\end{array}$} & \multirow[b]{3}{*}{$\begin{array}{c}L \\
(\mathrm{~mm})\end{array}$} & \multirow[b]{3}{*}{$\begin{array}{c}\text { Total } \\
\text { Depth } \\
D(\mathrm{~mm})\end{array}$} & \multirow{2}{*}{\multicolumn{2}{|c|}{ T- Beam Flange }} & \multirow{2}{*}{\multicolumn{2}{|c|}{ T-Beam Web (rib) }} & \multirow[b]{3}{*}{$\begin{array}{c}\text { Rate of } \\
\text { Loading } \\
(\mathrm{kN} / \mathrm{s})\end{array}$} & \multirow[b]{3}{*}{$\begin{array}{l}\text { Failure } \\
\text { Type }\end{array}$} & \multicolumn{12}{|c|}{ Sensor Location $(\mathrm{mm})$} \\
\hline & & & & & & & & & & & & & \multicolumn{2}{|c|}{1} & \multicolumn{2}{|c|}{2} & \multicolumn{2}{|l|}{3} & \multicolumn{2}{|c|}{5} & \multicolumn{2}{|c|}{6} & \multicolumn{2}{|c|}{8} \\
\hline & & & & & & & $\begin{array}{l}\text { Depth } \\
(\mathrm{mm})\end{array}$ & $\begin{array}{c}\text { Width } \\
W_{f} \\
(\mathrm{~mm})\end{array}$ & $\begin{array}{c}\text { Depth } \\
(\mathrm{mm})\end{array}$ & $\begin{array}{l}\text { Width } \\
W_{\text {rib }} \\
(\mathrm{mm})\end{array}$ & & & $X$ & Y & $X$ & $Y$ & $X$ & Y & $X$ & Y & $X$ & Y & $X$ & Y \\
\hline LC1M37 & 20 & 4 & 1256 & 2600 & 3210 & 560 & 180 & 500 & 380 & 180 & 4 & Tensile & 360 & 100 & 1000 & 270 & 1600 & 200 & 2200 & 140 & 2440 & 370 & 2810 & 200 \\
\hline LC2M37 & 20 & 4 & 1256 & 2600 & 3210 & 560 & 180 & 500 & 380 & 180 & 4 & Tensile & 460 & 300 & 900 & 240 & 1600 & 175 & 2000 & 160 & 2400 & 210 & 2800 & 190 \\
\hline LLR3 & 20 & 4 & 1256 & 2600 & 3210 & 560 & 180 & 500 & 380 & 180 & 5 & Tensile & 460 & 300 & 900 & 240 & 1600 & 200 & 2000 & 160 & 2420 & 230 & 2800 & 200 \\
\hline LLR1 & 20 & 4 & 1256 & 2600 & 3210 & 560 & 180 & 500 & 380 & 180 & 6 & Tensile & 460 & 300 & 900 & 240 & 1600 & 200 & 2000 & 160 & 2400 & 230 & 2800 & 200 \\
\hline
\end{tabular}

\section{FIG. 2}

Loading protocol used for testing of RC beams in the laboratory. The number of loading cycles applied for test specimen LC2M37 (load cycle number is indicated at peak for each loading cycle).

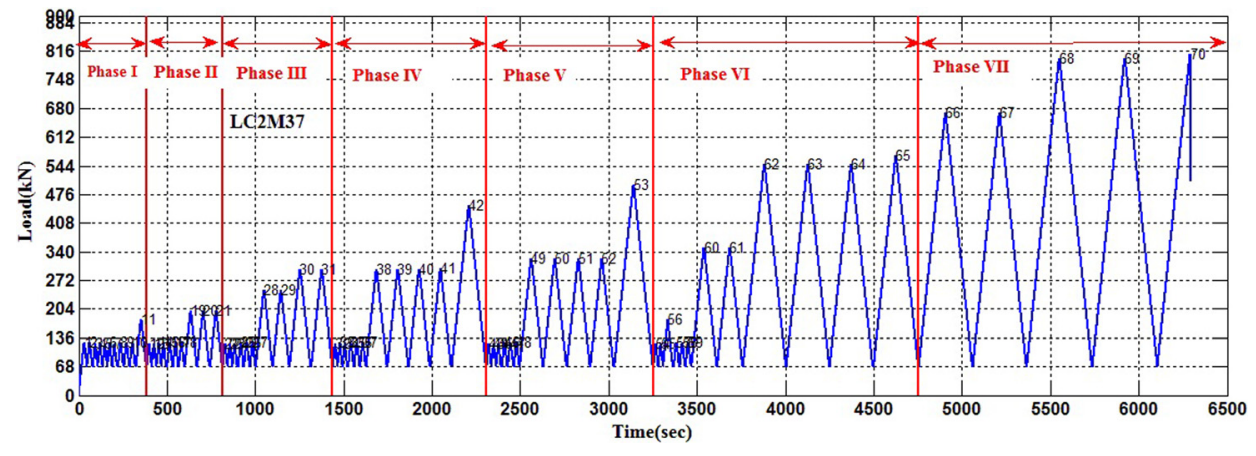

TABLE 2 Loading details and AE parameters of test specimens at different loading stages.

\begin{tabular}{|c|c|c|c|c|}
\hline Test Specimen & LC1M37 & LC2M37 & LLR3 & LLR1 \\
\hline Loading rate $(\mathrm{kN} / \mathrm{s})$ & 4 & 4 & 5 & 6 \\
\hline Number of phases & 7 & 7 & 6 & 6 \\
\hline Number of cycles & 70 & 69 & 57 & 56 \\
\hline Load at which first crack appeared $(\mathrm{kN})$ & 281 & 290 & 137 & 124 \\
\hline Failure load $(\mathrm{kN})$ & 810 & 811 & 797 & 801 \\
\hline Time of final failure (min) & 58 & 105 & 58 & 49 \\
\hline Cumulative hits (sum of all phases) & $1,112,669$ & 318,655 & 174,688 & 266,389 \\
\hline Number of hits in last phase & 123,003 & 123,109 & 59,963 & 89,711 \\
\hline Cumulative energy counts (sum of all phases) & $9,953,321$ & $9,952,427$ & $11,804,404$ & $24,987,722$ \\
\hline Energy counts in last phase & $3,954,329$ & $3,958,379$ & $5,569,472$ & $13,000,000$ \\
\hline Average amplitude (dB) (average of all phases) & 49.02 & 49.07 & 49.76 & 49.51 \\
\hline amplitude in last phase & 49.42 & 49.75 & 50.67 & 50.75 \\
\hline Average $b$-value (average of all phases) & 0.99 & 0.99 & 0.96 & 0.98 \\
\hline$b$-value of last phase & 0.89 & 0.91 & 0.87 & 0.85 \\
\hline Average energy per hit(average of all phases) & 22.81 & 23.56 & 58.75 & 81.93 \\
\hline energy per hit in last phase & 31.81 & 32.15 & 92.88 & 145.47 \\
\hline Average $I b$-value(average of all phases) & 1.21 & 1.22 & 1.16 & 1.24 \\
\hline$I b$-value in last phase & 1.14 & 1.12 & 1.08 & 1.09 \\
\hline
\end{tabular}


FIG. 3

Drop off $b$-value and $/ b$-value at peak load of a loading cycle ( $b$-value and $/ b$-value range is shown for 0-25 min of test time).

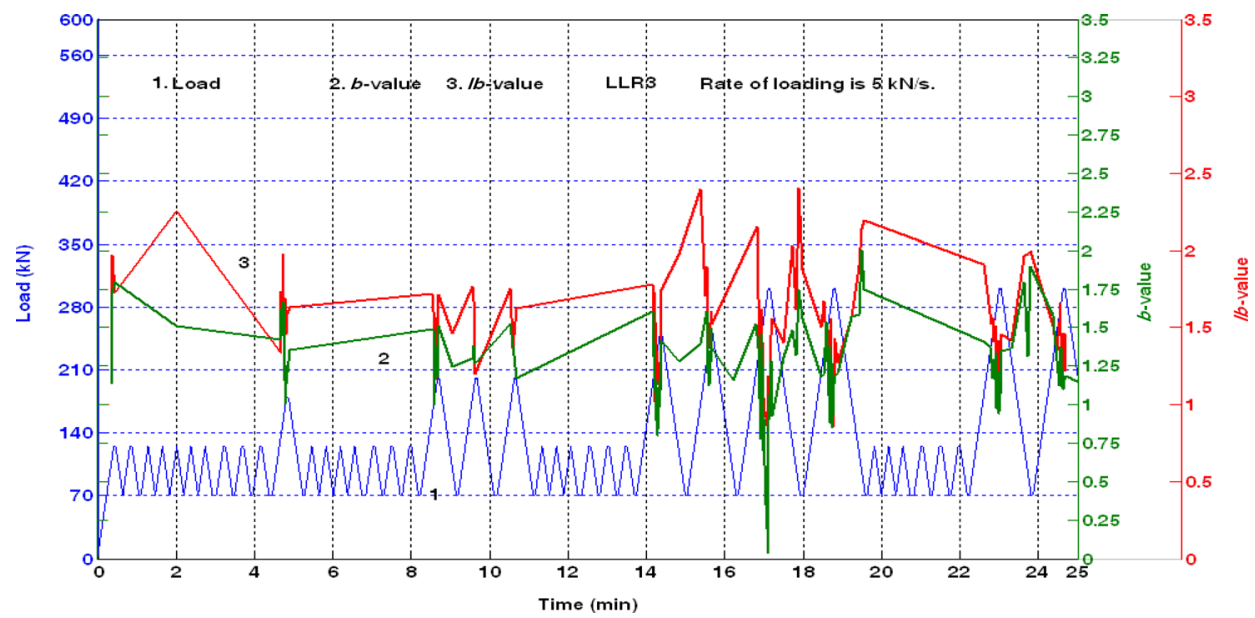

FIG. 4

(a) Variations of $I b$-values and energy counts as a function of time duration of the test (test specimen LLR3). (b) Variation of the

cumulative number of hits and $/ b$-value as a function of the load cycle (number) of the test (LLR3 specimen).
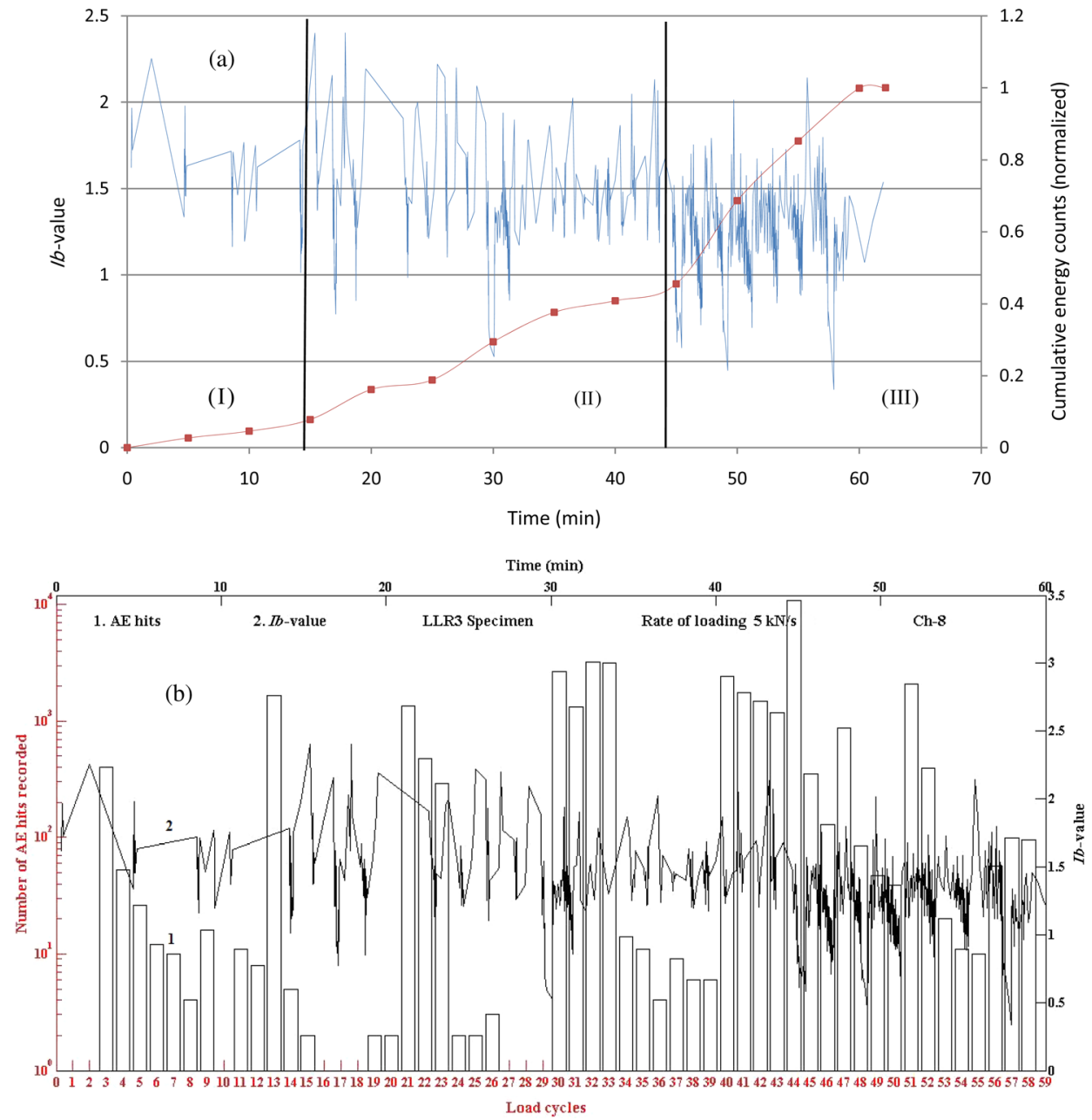

Copyright by ASTM Int'l (all rights reserved); Fri Jul 14 04:51:52 EDT 2017

Downloaded/printed by

Indian Inst of Science Bangalore (Indian Inst of Science Bangalore) pursuant to License Agreement. No further reproductions authorized. 


\section{AE INSTRUMENTATION}

A multichannel AE monitoring system consisting of resonant type AE differential sensors, preamplifiers, a data acquisition system, processing instrumentation, and a personal computer was used. The $2 \mathrm{D}$ locations ( $X$ and $Y$ coordinates) of the $\mathrm{AE}$ sensor's location are shown in Table 1 and also schematically in Fig. 1c. The $\mathrm{AE}$ transducers have peak sensitivity at $75 \mathrm{~dB}$ with reference to $1 \mathrm{~V} /(\mathrm{m} / \mathrm{s})(1 \mathrm{~V} / \mathrm{mbar})$ at a $54-\mathrm{kHz}$ frequency. All six sensors used are identical with regard to their size, shape, and sensitivity. The operating frequency of the sensor was 35 to $100 \mathrm{kHz}$. The AE signals were amplified with a gain of $40 \mathrm{~dB}$ in a preamplifier. The threshold value of $40 \mathrm{~dB}$ was selected to ensure a high signal to noise ratio. The total AE energy released was calculated by summing up the AE energy recorded by the six channels.

\section{LOADING PROCEDURE}

The loading pattern applied on the RC beam specimen (assumed as a beam in a bridge) is shown in Fig. 2. In this present study, a series of service-level force cycles are applied in between test trucks (TTs). These test trucks were chosen to represent the case of structural force testing in the field. TTs were variable in loading magnitude. The lesser force repetitions are indicative of service level forces. From Fig. 2, one can observe that a series of TTs was repeated. The reason for this is to study the effect of loading repetitions on the AE response. The RC beam specimen is subjected to loading protocol that has two types of pattern as shown in Fig. 2. The first pattern has a force intensity with relatively lesser peak and constitutes transport vehicle (TV) effect. The second pattern has a higher peak force that constitutes an elevated simulated test truck (ESTT). The two patterns together give the single-loading phase. Each loading phase has varying peak force.

\section{Results and Discussion}

The rate of loading, number of loading phases, and total number of recorded AE hits, events, energy, and counts are shown

\section{FIG. 5}

(a) Variation of RA and Ib-value as a function of the time duration of the test (test specimen LLR3, channel 3 near tensile cracking zone). (b) Variation of RA and $/ b$-value as a function of the time duration of the test (test specimen LLR3, channel 8 near shear cracking zone).
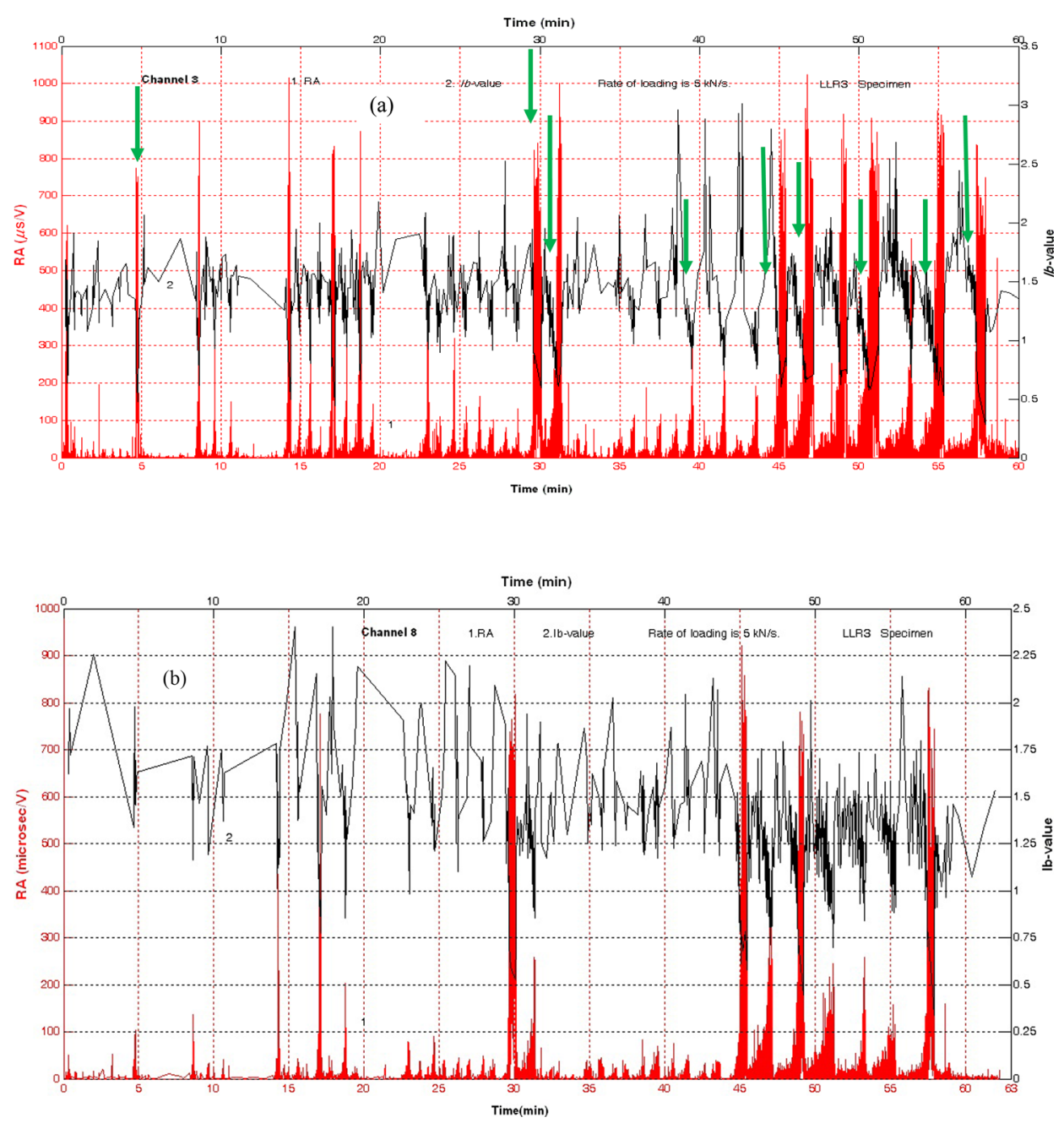
in Table 2. In the present study, $\mathrm{AE}$ based $b$-value was calculated for each channel for a group of 125 hits using the method described in Refs [40,41]. In general, $I b$-value is used to check and improve the $b$-value plots by suitably filtering the $\mathrm{AE}$ amplitude data and restricting it to the liner trend of the frequency-amplitude distribution. Ib-value analysis has been performed in the present study using Eq 4. By following the method suggested in Refs [40,48], a group of 125 recorded AE hits are taken with a lag of 25 hits and based on statistical values, i.e., the mean and standard deviation of recorded AE hits, $I b$-values are computed using a computer program developed by the authors. From Fig. 3, the accuracy of $I b$-value computations is validated, as the pattern of both the $b$-value and $I b$-value is same. It was observed that the $I b$-value follows the same trend as the $b$-value, wherein it reaches minimum value at the peak force in a loading cycle. It is observed from the plots in Fig. 3 that the lowest $I b$-values occur at the peak force in each force cycle.
We would like to point out that the uncorrected $I b$-value is $\sim 0.05$ only. However, the equation suggested originally by Shiotani et al. along with the multiplication factor of 20 for comparing the $I b$-value (after correction) with the widely accepted $b$-value of 1.0 has been followed here and elsewhere to investigate its precursory variations before the ultimate fracture of the test beam/test specimens [48-50]. Also, it was observed that the $I b$-value is greater than the $b$-value. The reason could be that the AE-based $b$-value and $I b$-value become equal only in situations where the cumulative number of AE hits at the upper amplitude limit is 1.0 or 2.0 and not more [40]. Further, the mean amplitude $(\mu)$ and standard deviation $(\sigma)$ also control the $I b$-value [40,48-40]. Since the $I b$-value is statistical in nature, for similar sensing grids and concretes, the attenuation effect may not dominate the response.

During the fracture process in RC structures, distinct stages of micro-cracking activity, namely initiation, stable growth, and
FIG. 6

(a) Variation of the $/ b$-value and strain in steel as a function of the time duration of test (test specimen LLR3). (b) Variation of Ib-value and mid-span displacement as a function of the time duration of test (test specimen LLR3).
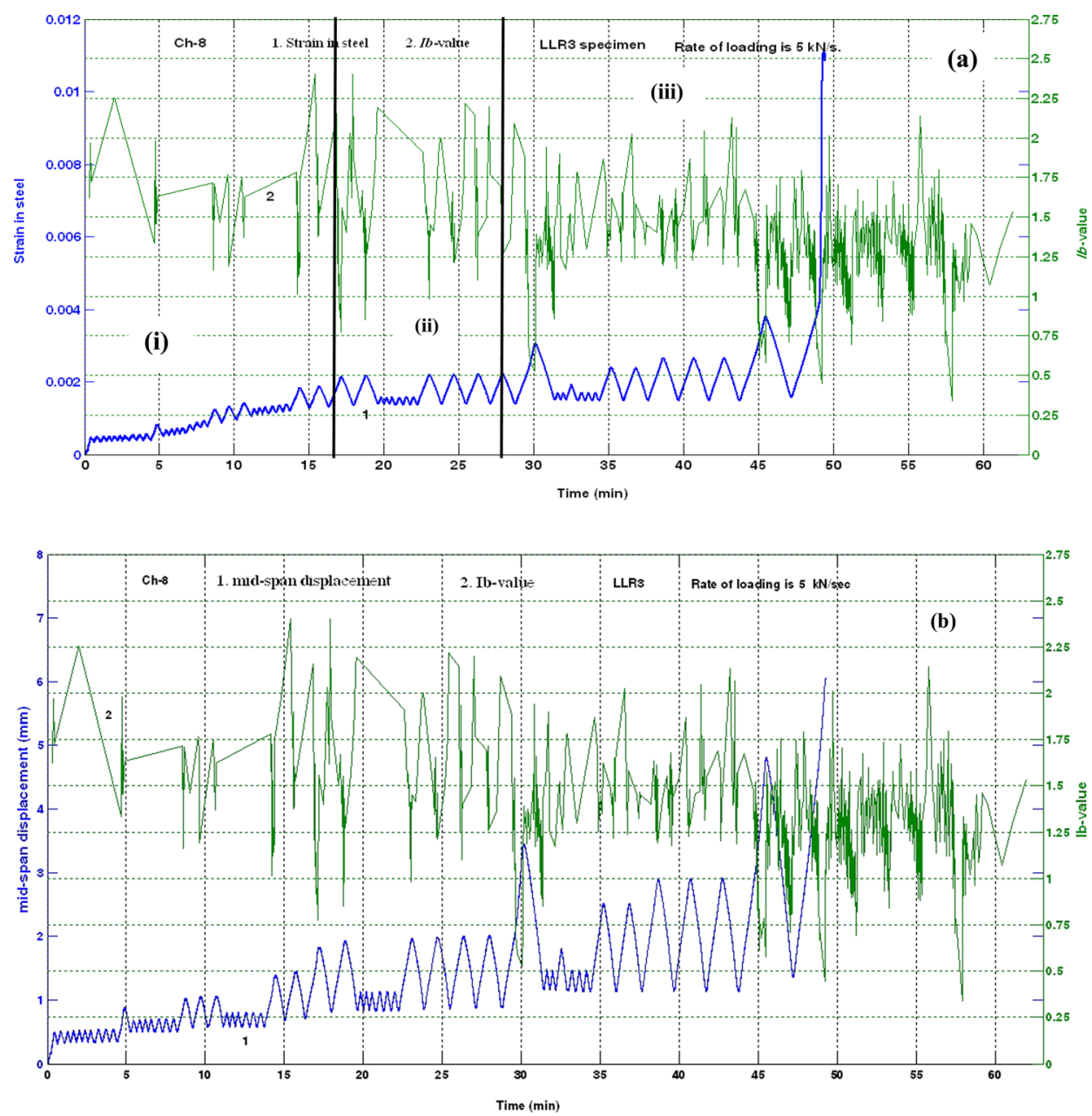
nucleation takes place prior to the final failure [3]. The AE statistical behavior of each individual stage is dependent on the number and size distribution of micro-cracks. The growth and coalescence of micro-cracks formed during the crack propagation are sources of AE. As most AE signals are generated during the formation of micro-cracks, they are, therefore, likely sources for occurrence of the lowest $I b$-values. Another source of AE is the bond failure between steel reinforcement and concrete and also between coarse aggregate and cement mortar, and this may be responsible for fluctuations in $\mathrm{AE}$ generation and hence rapid changes in $I b$-values.

Higher AE activity, such as a large number of AE events with higher intensity events, are also observed around the last loading phases. These observations further prove that the instance of damage initiation is predicted by the lowest $I b$-value. A low $I b$-value may be due to initiation of micro-cracks and existing crack openings. The increase in $I b$-value during the unloading in a loading cycle could be related to shear cracks development and crack sliding.

\section{COMPARISON OF AE ENERGY COUNTS WITH VARIATION IN Ib-VALUE}

Energy counts are another important AE parameter for damage assessment. Hence, it is shown by plotting on the $Y 2$ axis (secondary axis of $Y$ ) along with the $I b$-value on the $Y 1$ axis (primary axis of $Y$ ) as a function of time in Fig. 4a. Fig. 4a shows normalized energy count (cumulative) versus normalized time. It was noticed that the curve has distinct slopes from 0.0 to 0.4 , 0.4 to 0.75 , and from 0.75 to 1.00 time frames. This clearly indicates that those are the stages of damage accumulation. The AE hits (which are another crack damage index parameter) and $I b$ values are plotted as a function of the force cycles (number) in Fig. 4b. A clear indication observed was that the $I b$-value concentration increases at higher loading cycles (or at greater forces). As the fracture process was nearly complete during the last few force cycles, $\mathrm{AE}$ were occurring quite rapidly with greater amplitude events dominating, and as a result of which the $I b$-value decreases fast showing an overlapping trend as shown in Figs. $\mathbf{4 a}$ and $\mathbf{4 b}$.
FIG. 7

(a) Variation of AE energy counts and $/ \mathrm{b}$-value as a function of the time duration of test (test specimen LLR3, channel 3). (b) Variation of AE energy counts $I b$-value as a function of the time duration of the test (test specimen LLR3, channel 8).
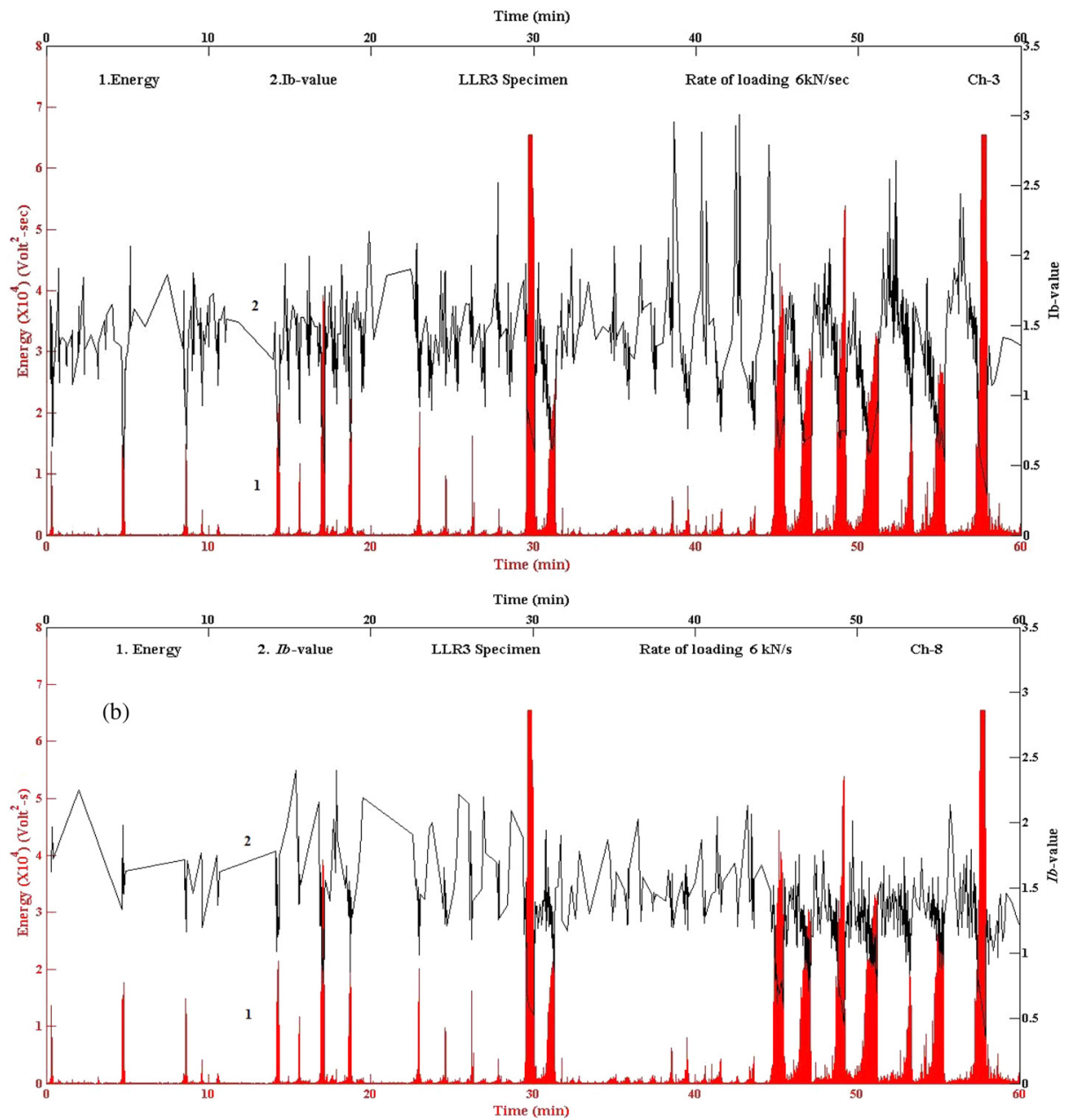


\section{COMPARISON OF AE FREQUENCY CHARACTERISTICS WITH VARIATION IN $I b$-VALUE}

Since the stresses change throughout the length of the beam (shearing in two sides, no shear in the mid-span), it is particularly interesting to check the characteristics of the AE, such as frequency content and RA. These have shown a potential in classification of the AE signals. The AE characteristics contribute not only to distinguish the intensity of damage but also the mode (tensile mode or shear mode), which is of significance for structural health monitoring [48].

Fig. 5a shows the frequency characteristics, such as RA for channel 8 (Ch-8), which are close to the shear cracks, versus these characteristics for $\mathrm{Ch}-3$, which are in the tensile zone. A higher frequency and lower RT and RA were observed for Ch-3. Fig. 5b shows the variation of RA with an $I b$-value in the shear zone. The $I b$-value is on the descent when RA values increase a lot. The arrows are shown at characteristic moments. Also, it was observed that at these moments, AF goes down. These correlate very well showing that extensive damage that compromises the capacity is followed by an $\mathrm{I} b$-value drop and RA increase. In the case of $\mathrm{Ch}-8$, which is present in shear zone, there is no significant RA until the 15th minute because tensile cracks occur first and shear cracks occur later. As the specimen reaches ultimate force, shear cracks are significant along with the tensile failure.

RA and $I b$-values are useful parameters for damage assessment. During the replay of the AE data, we noticed that the RA and $I b$-values data of AE detected by $\mathrm{AE}$ sensors 3 and 8 at channels 3 and 8 , respectively, showed some very interesting results. After visual inspection of cracks, we realized that those two sensors are quite close to the cracks developed in the test beams, particularly in specimen LLR3. Among the two, sensor 3 was quite close to the tensile cracks and sensor 8 was close to the shear cracks. Hence, we took into account data obtained at those two sensors (ignoring the attenuation suffered by the AE signals) and plotted the results as shown in Fig. 5a for the data of Ch-3 (sensor 3 ) and Fig. 5b for the data of Ch-8 (sensor 8).

\section{COMPARISON OF VARIATION IN Ib-VALUE WITH STRAIN IN STEEL AND MID-SPAN DISPLACEMENT}

The computed AE-based $I b$-values are correlated to physical measurements such as strain in tensile reinforcement, mid-span displacement, and most importantly the evolution of cracks on the specimen. Fig. 6 a shows variation of the $I b$-value with strain in steel (at mid-span), and Fig. 6b shows variation of the $I b$-value with recorded mid-span displacement. Both are plotted as a function of time along with $I b$-values in the plots. The fluctuations of the $I b$-value computed using AE data recorded by Ch-3 coincide with the local maxima in force history. The same was more or less observed for the other channels. It is possible that after severe damage some of the AE sensors may not receive all the emitted $\mathrm{AE}$ hits due to excessive scattering and attenuation. Therefore, for a severely damaged structure (approximately more than $60 \% \varepsilon_{\text {steel }}$ ), the continuity of the medium may not exist anymore for the $\mathrm{AE}$ waves to smoothly propagate. But at $60 \%$ of $\varepsilon_{\text {steel }}$ the RC beam is already critically damaged.

Also, one can observe that very high energy was released at the final loading cycles as shown in Figs. $\mathbf{7 a}$ and $\mathbf{7 b}$. One can observe the characteristic moments in Figs. $\mathbf{7 a}$ and $\mathbf{7 b}$ around 45 to $55 \mathrm{~min}$. Also, it was observed that at these instants $I b$-values were dropped, and very high energy was released. The $I b$-value shows a reasonable decrease for the successive phases as shown in Fig. 8a. In the present study, for each loading cycle, the minimum and maximum $I b$-values were observe for each loading phase recorded by Ch- 8 (LLR3 specimen). Also, the $I b$-value is obtained as the mean of the minimum and maximum values at the end of each loading stage and loading phase, and it shows a decreasing trend in both the cases as shown in Fig. 8a, in which the data of Ch- 8 of the LLR3 test specimen are plotted. The minimum and maximum values of the $I b$-value as a function of the loading cycle number of the same channel and specimen are plotted in Fig. 8b. The changes noticed in their values versus the number of loading cycles increase, and the interpretation of results with regard to the formation and progress of microcracking and the opening of macro-cracks (Fig. 8b) is quite similar to the results reported by Colombo et al. [41]. The inclination or development of the variation of the $I b$-value was plotted against for loading cycle. A decrease in the $I b$-value may be due

FIG. 8 Plots showing the lb value as a function of (a) loading phase and (b) loading cycle number [41].
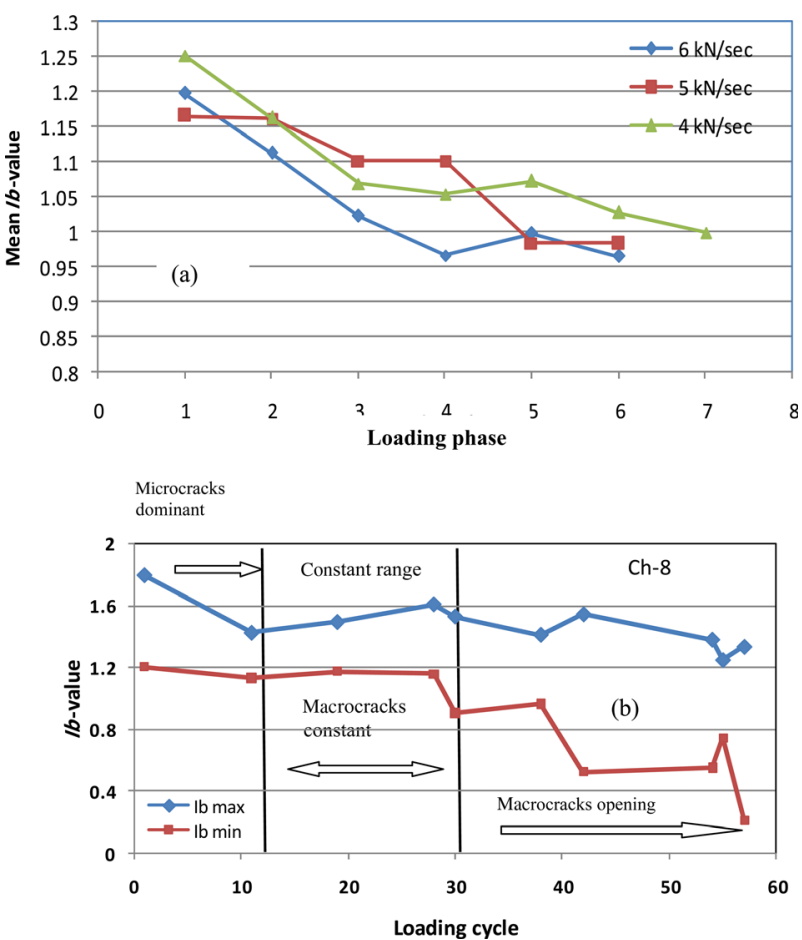
to initiation of micro-cracks and existing crack openings. The increase in the $I b$-value during unloading in a cycle could be related to shear crack development and crack sliding.

In the present study, an attempt has been made to compare the $I b$-value to "minor damage," "intermediate damage," and "heavy damage" through correlation to the physical state of the specimens. One can classify the physical state of the specimen in the context of fracture mechanics as two states vis-a-vis prepeak and post-peak. More precisely, as (i) elastic and inelastic if it is steel and (ii) softening if it is concrete. Concrete cracks first initially even at low forces, and next the steel yields if it is under-reinforced. As steel yields, it starts transferring stress to concrete in compression, and finally the concrete is crushed in compression. In an over-reinforced RC beam, steel does not yield but concrete crushes much before. That is why the deflection at ultimate failure in an under-reinforced beam is much larger than that of an over-reinforced beam.

It may be possible to classify the damage according to the state of strain in steel or in concrete. Damage is certainly an indication of strain. Concrete in compression shows some spalling at a strain of 0.002 and completely crushes at a strain of 0.003 or sometimes 0.0035 . If it is confined concrete, it is 0.004 . Similarly, steel yield strain depends on whether it is mild steel or high-strength steel. The damage in concrete that finally decides the state of the specimen can be called minor when the compression strain in concrete is less than 0.002 , intermediate when
FIG. 9

(a) Load-time plot. Variation of damage parameter and Ibvalue of $A E$ as a function of time of test specimen LLR3 ((b) for $\mathrm{Ch}-3$ in the tensile zone and (c) for $\mathrm{Ch}-2$ in the shear zone).
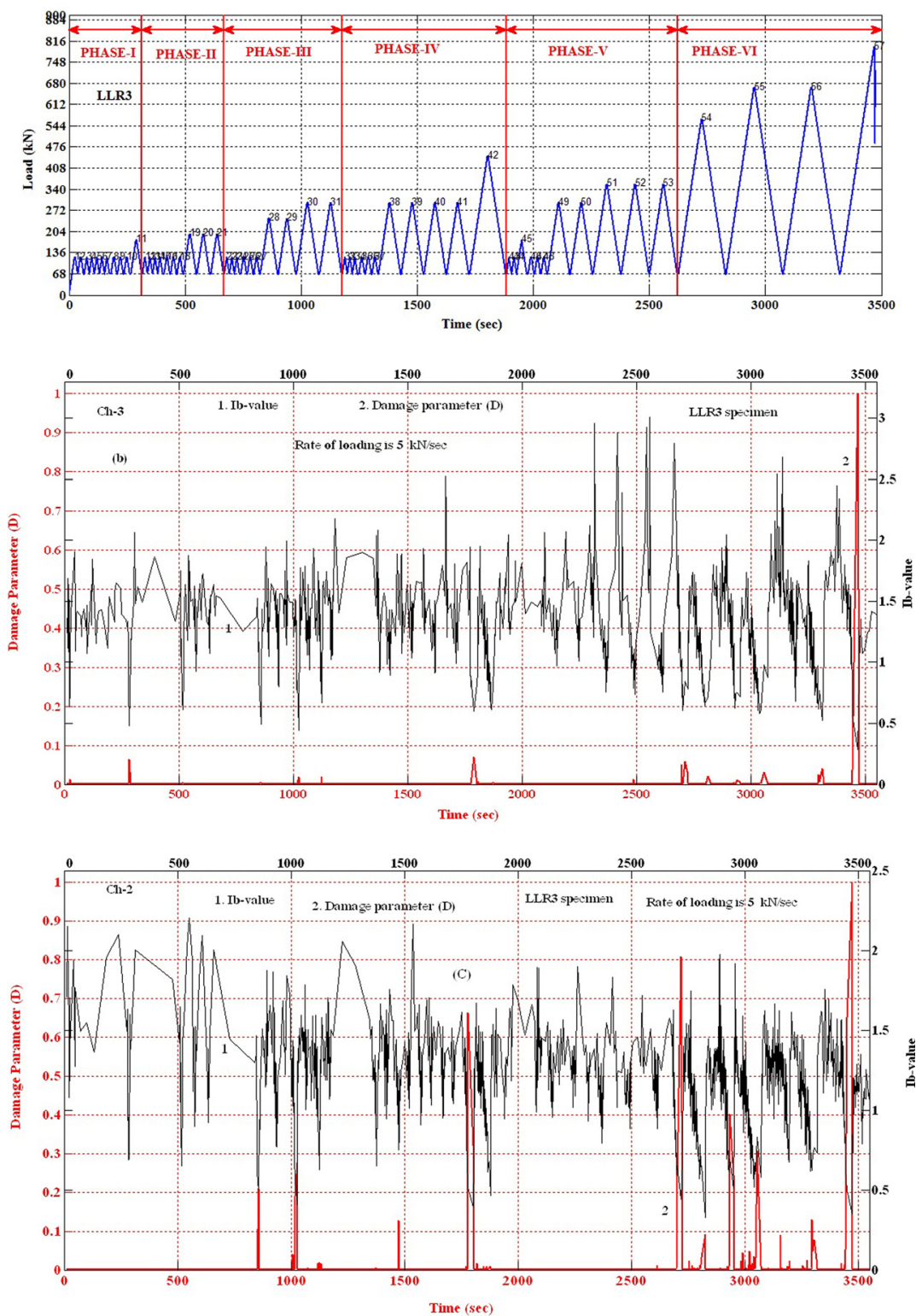
TABLE 3 Ib-values of AE due to the evolution of cracks in the tensile and shear zones (test specimen LC2M37).

\begin{tabular}{|c|c|c|c|c|c|c|}
\hline \multirow[b]{2}{*}{ Load $(\mathrm{kN})$} & \multicolumn{2}{|c|}{$I b$-Value } & \multicolumn{2}{|c|}{ Crack Present in } & \multicolumn{2}{|c|}{ Crack Location } \\
\hline & Ch-8 (in Shear Zone) & Ch-3 (in Tension Zone) & Tension Zone & Shear Zone & In Flange & In Web \\
\hline 241 & 1.047 & 1.153 & Crack 1 & - & - & Crack-1 \\
\hline 241 & 1.047 & 1.153 & - & Crack 2 & - & Crack-2 \\
\hline 253 & 0.851 & 1.206 & - & Crack-3 & - & Crack-3 \\
\hline 290 & 1.124 & 0.827 & Crack-4 & - & - & Crack-4 \\
\hline 294 & 1.094 & 1.196 & - & Crack-5 & Crack-5 & \\
\hline 294 & 1.094 & 1.196 & Crack-6 & - & - & Crack-6 \\
\hline 294 & 1.094 & 1.196 & Crack-7 & - & - & Crack-7 \\
\hline 300 & 1.117 & 1.075 & Crack-8 & - & - & Crack-8 \\
\hline $294 \& 300$ & $1.094 \& 1.117$ & $1.196 \& 1.075$ & Crack-9 & - & - & Crack-9 \\
\hline 390 & 1.003 & 0.988 & - & Crack-10 & - & Crack-10 \\
\hline 256 & 1.137 & 1.292 & Crack-12 & - & - & Crack-12 \\
\hline 402 & 1.323 & 1.187 & - & Crack-13 & - & Crack-13 \\
\hline 402 & 1.323 & 1.187 & - & Crack-14 & - & Crack-14 \\
\hline 402 & 1.323 & 1.187 & - & Crack-15 & - & Crack-15 \\
\hline 386 & 1.056 & 1.008 & - & Crack-16 & - & Crack-16 \\
\hline 478 & 1.043 & 1.019 & - & Crack-17 & - & Crack-17 \\
\hline 350 & 1.224 & 1.260 & - & Crack-18 & - & Crack-18 \\
\hline 550 & 1.056 & 1.024 & Crack-19 & - & Crack-19 & \\
\hline 460 & 1.060 & 1.145 & - & Crack-20 & - & Crack-20 \\
\hline 526 & 0.453 & 0.606 & - & Crack-21 & - & Crack-21 \\
\hline 526 & 0.453 & 0.606 & - & Crack-22 & - & Crack-22 \\
\hline 550 & 1.056 & 1.024 & Crack-23 & Crack-23 & - & \\
\hline 526 & 0.453 & 0.606 & - & Crack-24 & - & Crack-24 \\
\hline 631 & 0.908 & 1.437 & Crack-25 & - & - & Crack-25 \\
\hline 631 & 0.908 & 1.437 & - & Crack-26 & - & Crack-26 \\
\hline 780 & 0.137 & 0.615 & Crack-27 & - & Crack-27 & - \\
\hline 780 & 0.137 & 0.615 & Crack-28 & - & Crack-28 & - \\
\hline
\end{tabular}

it is 0.002 , and heavy when it is 0.003 or 0.0035 . Authors have adopted these limits based on IS 456-2000 [52], and the comparison of the $I b$-value with strain in steel is shown in Fig. $\mathbf{6 a}$.

Displacement may not define damage because displacement depends on span and cross-sectional details and not merely on the material. It is global while strain is local, and therefore strain should decide the state of damage. A deflection value of span/ 250 (IS 456-2000) is a notional value from the user's point of view regarding aesthetics, comfort, and feelings of safety [52]. In fact, at a value of span/250 no damage would have occurred, and that is why the code of practice (IS 456-2000) prescribes that as a safe deflection [50-52].

TABLE 4 Ib-values of AE due to the evolution of cracks in tensile and shear zones (test specimen LLR2).

\begin{tabular}{|c|c|c|c|c|c|c|}
\hline \multirow[b]{2}{*}{ Load $(\mathrm{kN})$} & \multicolumn{2}{|c|}{$I b$-Value } & \multicolumn{2}{|c|}{ Crack Present in } & \multicolumn{2}{|c|}{ Crack Location } \\
\hline & Ch-8 (in Shear Zone) & Ch-3 (in Tension Zone) & Tension Zone & Shear Zone & Flange & Web \\
\hline 178 & 1.182 & 1.047 & Crack-1 & - & - & Crack-1 \\
\hline 200 & 0.96 & 0.92 & - & Crack-2 & - & Crack-2 \\
\hline 154 & 1.19 & 0.96 & - & Crack-3 & - & Crack-3 \\
\hline 300 & 1.16 & 0.99 & Crack-4 & - & - & Crack-4 \\
\hline 300 & 1.16 & 0.99 & - & Crack-5 & - & Crack-5 \\
\hline 300 & 1.16 & 0.99 & Crack-6 & - & - & Crack-6 \\
\hline 300 & 1.16 & 0.99 & - & Crack-7 & - & Crack-7 \\
\hline 89 & 1.18 & 1.29 & Crack-8 & - & - & Crack-8 \\
\hline 319 & 0.44 & 1.21 & - & Crack-9 & - & Crack-9 \\
\hline 319 & 0.44 & 1.21 & - & Crack-10 & - & Crack-10 \\
\hline
\end{tabular}


TABLE 5 Ib-values of AE due to the evolution of cracks in tensile and shear zones (test specimen LLR3).

\begin{tabular}{|c|c|c|c|c|c|c|}
\hline \multirow[b]{2}{*}{ Load $(\mathrm{kN})$} & \multicolumn{2}{|c|}{$I b$-Value } & \multicolumn{2}{|c|}{ Crack Present in } & \multicolumn{2}{|c|}{ Crack Location } \\
\hline & Ch-8 (in Shear Zone) & Ch-3 (in Tension Zone) & Tension Zone & Shear Zone & Flange & Web \\
\hline 115 & 1.627 & 1.214 & & Crack-1 & & Crack-1 \\
\hline 247 & 1.695 & 1.215 & Crack-2 & & & Crack-2 \\
\hline 520 & 1.023 & 0.836 & Crack-3 & & & Crack-3 \\
\hline 203 & 1.453 & 1.239 & & Crack-4 & & Crack- 4 \\
\hline 288 & 1.493 & 2.177 & & Crack-5 & & Crack-5 \\
\hline 269 & 1.637 & 1.566 & & Crack-6 & & Crack-6 \\
\hline 189 & 1.194 & 1.169 & & Crack-7 & & Crack-7 \\
\hline 137 & 1.127 & 0.262 & Crack-8 & & & Crack- 8 \\
\hline 287 & 1.623 & 1.367 & & Crack-10 & & Crack-10 \\
\hline 242 & 1.503 & 1.415 & Crack-11 & & & Crack-11 \\
\hline 382 & 1.202 & 1.081 & & Crack-12 & & Crack-12 \\
\hline 382 & 1.202 & 1.081 & & Crack-13 & & Crack-13 \\
\hline 195 & 2.132 & 0.841 & & Crack-14 & Crack-14 & \\
\hline 512 & 1.327 & 1.105 & & Crack-15 & & Crack-15 \\
\hline 665 & 1.163 & 1.015 & & Crack-16 & & Crack-16 \\
\hline 415 & 1.262 & 1.358 & & Crack-17 & & Crack-17 \\
\hline 415 & 1.262 & 1.358 & & Crack-18 & & Crack-18 \\
\hline 752 & 0.529 & 0.407 & Crack-19 & & & Crack-19 \\
\hline 752 & 0.529 & 0.407 & Crack-20 & & Crack-20 & \\
\hline 752 & 0.529 & 0.407 & Crack-21 & & & Crack-21 \\
\hline
\end{tabular}

\section{EFFECT OF LOADING RATE ON Ib-VALUE VARIATION}

In case of a low rate of loading, there is ample time for the damage to grow, and there will be a scope to weaken the material. In this case, the loading rate is less, there is less scope of micro-cracks to develop, and there is also less chance for the micro-cracks to spread fast. It was observed that the recorded $\mathrm{AE}$ events are fewer in number when the rate of loading is high, as shown in Table 2.

$\mathrm{AE}$ released during cycling loading of RC structures could be due to different sources such as crack opening and crack propagation or friction between existing crack surfaces, which could occur during the opening or closure of cracks. This means that in such structures damage accumulation could be related to a variation of the $\mathrm{AE}$ patterns. The rate of loading influences the $\mathrm{AE}$ released and fracture behavior of concrete. The rate of loading can also accelerate the micro-crack damage, which is accompanied by the release of AE. If the rate of loading is too fast (more than what is suggested by the ASTM), there can be a surge or heavy rush of $\mathrm{AE}$ that the data logging equipment cannot cope with. In such a case, the number of AE events (or hits) recorded would be less giving rise to greater $b$-values. The fluctuations in $I b$-value variation are greater when the rate of loading is high; in other words, when the rate of loading is high, the damage is high and the $I b$-value is very small. One can observe that the specimen LC2M37 underwent less damage at a smaller rate of loading in terms of the data of the $I b$-value, $I b$-value, and AE energy per hit. From Fig. $\mathbf{8 b}$, one can observe that there is a distinction in $I b$-value with time due to change in rate of loading.

During higher loading rates, quick cracking development takes place, which leads to rapid fluctuations, and also there were drops in the $I b$-values. Also, it was observed that the material behaves in a more brittle way at higher loading rates (or in higher strain rates), and the $I b$-values are lower on average as a few and strong cracking AE events with higher energy are created. But when the loading rate is low, more $\mathrm{AE}$ and with less AE energy is released.

\section{AE MEASUREMENTS OF THE DAMAGE PARAMETER (D)}

The variation in $I b$-value is compared with a damage parameter (D) proposed in Refs [52-55].

$$
D=\sum 10^{3 \cdot\left(\frac{A_{d B}}{20}\right)}
$$

The parameter $(D)$ describes the damage taking place in a materials under stress. $D$ is also related to the change of porosity $(n)$ in the concrete.

$$
n(\%)=\frac{V_{v}}{V} \times 100
$$

where:

$V_{v}=$ the volume of voids (or volume of cracks) present in the specimen, and

$V=$ the total volume of the specimen. 
FIG. 10

Schematic representation of cracks developed during the fracture process at different stages of loading of three test beams: (a) LC2M37, (b) LLR2, and (c) LLR3.
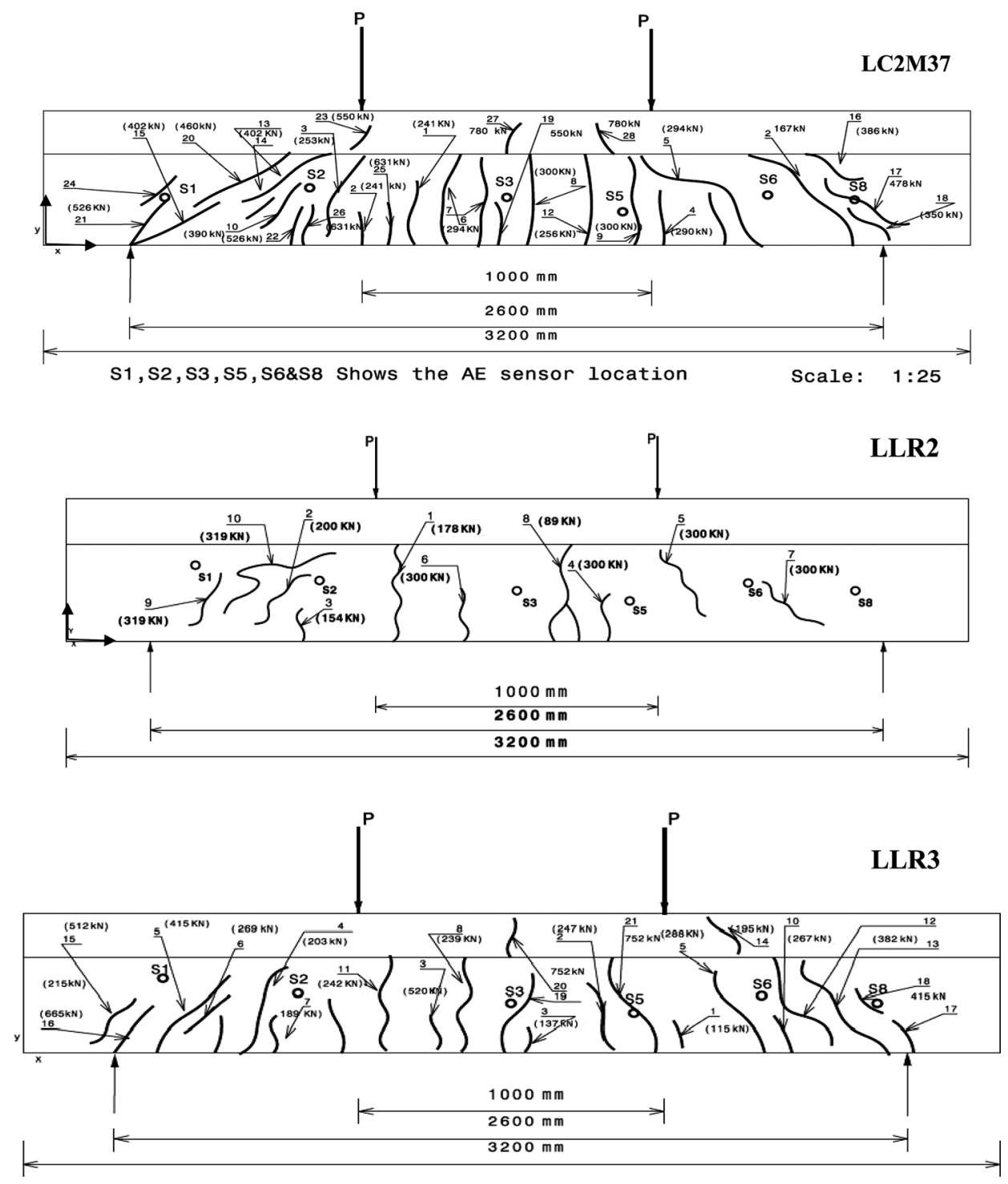

$D$ is proportional to the cube of the mean of the crack length [52-54]. In fact, the Gutenberg-Richter $b$-value and inferred rupture length distribution exponent $(D)$ are applicable for concrete subjected to flexural, compressive, and tensile forces. This is because the same scaling of frequency-magnitude distribution is also observed in double torsion (tensile) samples by Hatton et al. [54]. The scaling of frequency-magnitude distribution itself is affected by different loading conditions as observed by Ref [55], and then the absolute $b$-value and its progress may also be affected by different loading conditions including the rate of loading. The number of AE hits recorded and the damage parameter $(D)$ are directly proportional to each other, but both together are inversely proportional to the $b$ value. The loading phases applied on specimen LLR3 as shown in Fig. 9a were compared with the $I b$-value. At the higher loads, i.e., the crack formation initiates, the number of $\mathrm{AE}$ hits released was high and $D$ also increased, but the $I b$-value goes down as shown in Figs. 9b and 9c. At final failure, $D$ reached 1.0 when the $I b$-value dropped to minimum.

\section{CORRELATION OF Ib-VALUE WITH EVOLUTION OF CRACKS ON THE SPECIMEN}

The correlation of the $I b$-value with crack pattern is shown in Tables 3-5. The cracks developed are shown schematically in Fig. 10. As the forces applied were cyclic, considerable damage occurred at the peak forces of the initial phase. Formation of micro-cracks was observed at the peak of the force, which was accompanied by an increase in AE. The $I b$-value plot showed a sudden drop, indicating damage occurred within the beam. As 
the loading phase proceeded further, higher peak forces were applied with the same rate of loading. Visible cracks appeared on the surface of the beams in both shear and tensile zones. At the loading phase prior to the failure, branching of cracks was observed, showing $I b$-value concentration irrespective of the highest peaks. A large number of AE also occurred, which indicated major damage. During failure, the cracks open up vigorously. The $I b$-value that is coarse, suddenly drops to the minimum, and at this stage the specimen failed.

\section{Conclusions}

The $I b$-value can be considered to study the progress of damage during propagation and growth of micro- and macro-cracks from a state of no damage until the ultimate failure of the test object under stress. The AE data obtained can also be normalized accordingly for a better appreciation. The given below major conclusions are drawn from the present study.

1. $I b$-values are typically larger than $b$-values. It was observed that both $b$-value and $I b$-value show similar trends in concrete with regard to variations with force but only different values.

2. When the $I b$-value goes down, AE events with high RA values have been registered implying that major cracking is taking place in the test beam at these intervals. At these instants, high values of RA are observed, and on the contrary the AF was low.

3. When the sensor is near to tensile cracks, an AE with higher frequency and lower RA was observed.

4. When the loading rate is faster, quick cracking development occurs, leading to more fluctuations while the $I b$-value decreases. Since the material behaves in a more brittle way at higher loading rates (or in higher strain rates), the $I b$-values on an average are low as a few and strong cracking $\mathrm{AE}$ events are created, which is in contrast to more and weaker for a low rate of loading (or low strain rate).

5. $I b$-value analysis is useful in evaluating the status of damage in RC beams and also in structures in situ, as the instance of damage initiation can be predicted by the lowest $I b$-value. It has also been observed in the present study that when the rate of loading is high, $I b$-values attain minimum quite fast.

6. Fluctuations of RA and AF that show the temporary shift between small- and large-scale events of AE coincide with the drops (fluctuations) of $I b$-value.

\section{ACKNOWLEDGMENTS}

This work was financially supported partly by Bhabha Atomic Research Centre (BARC) Mumbai, India under grant number SID/IISc/PC-99191 and also financially supported partly by CiSTUP, Indian institute of Science, Bangalore, India under grant number CIST/MCV/RV/008.

\section{References}

[1] Suresh, S., Fatigue of Materials, Cambridge Univ., Cambridge, UK, 1991.

[2] Naik, T. R., Sing, S. S., and Ye, C., "Fatigue Behavior of Plain Concrete Made With or Without Fly Ash," $C B U$ Report 181, Center for Byproducts Utilization, Department of Civil Engineering and Mechanics, Univ. of Wisconsin, Milwaukee, WI, 1993.

[3] Karihaloo, B. L., Fracture Mechanics and Structural Concrete, Longman Scientific \& Technical, New York, 1995.

[4] Neal, J. A. and Kesler, C. E., "The Fatigue of Plain Concrete," Proceedings of the International Conference on the Structure of Concrete and its Behavior Under Load, London, UK, Sept 28-30, E. Brooks, and K. Newman, Eds., Cement \& Concrete Association, London, 1965, pp. 226-237.

[5] Raithby, K. D. and Whiffin, A. C., "Failure of Plain Concrete Under Fatigue Loading-A Review of Current Knowledge," RRL Report LR 231, Ministry of Transport, Road Research Laboratory, Crowthorne, UK, 1968.

[6] Murdock, J. W. and Kesler, C. E., "Effect of Range of Stress on Fatigue Strength of Plain Concrete Beams," ACI J., Vol. 55, No. 8, 1958, pp. 221-231.

[7] Shah, S. G., Ray, S., and Chandra Kishen, J. M., "Fatigue Crack Propagation at Concrete-Concrete Bi-Material Interfaces," Int. J. Fatigue, Vol. 63, 2014, pp. 118-126.

[8] Murdock, J. and Kesler, C. E., "The Mechanism of Fatigue in Concrete," Report No. 587, Univ. of Illinois, Champaign, 1960.

[9] Boswell, L. F. and Chen, Z., "General Criterion for Fatigue Failure of Plain Concrete," Int. J. Solids Struct., Vol. 23, No. 5, 1987, pp. 621-630.

[10] Foreman, R. G., Peary, V. E., and Engle, R. M., "Numerical Analysis of Crack Propagation in Cyclic-Loaded Structures," J. Basic Eng., Vol. 89, No. 3, 1967, pp. 459-464.

[11] Nordby, G. M., "Fatigue of Concrete-A Review of Research,” ACI J., Vol. 55, No. 2, 1958, pp. 191-220.

[12] Murdock, J. W., "A Critical Review of Research on Fatigue of Plain Concrete," Engineering Experiment Station Bulletin No. 475, Univ. of Illinois, Champaign-Urbana, 1965.

[13] Hilsdorf, H. K. and Kesler, C. E., "Fatigue Strength of Concrete Under Varying Flexural Stresses," ACI J., Vol. 63, No. 10, 1966, pp. 1059-1076.

[14] ACI Committee 215, "Consideration for Design of Concrete Structures Subjected to Fatigue Loading," ACI Manual of Concrete Practice, Part 1, ASME, New York, 1990, pp. 215R-1-215R-25.

[15] Sparks, P. R. and Menzies, J. B., "The Effect of the Rate of Loading Upon the Static and Fatigue Strengths of Plain Concrete in Compression," Mag. Concrete Res., Vol. 75, No. 83, 1973, pp. 73-80.

[16] Galloway, J. W. and Raithby, K. D., "Effects of Rate of Loading on Flexural Strength and Fatigue Performance Of Concrete," TRRL Report LR 547, Dept. of the Environment, Transport and Road Research Laboratory, Crowthorne, UK, 1973.

[17] Raithby, K. D. and Galloway, J. W., "Effects of Moisture Condition, Age, and Rate of Loading on Fatigue of Plain Concrete," Fatigue of Concrete, ACI Special Publication, 
SP-41, American Concrete Institute, Farmington Hills, MI, 1974, pp. 15-34.

[18] Holmen, J. O., "Fatigue of Concrete by Constant and Variable Amplitude Loading," ACI Special Publication, SP-75, American Concrete Institute, Detroit, MI, 1982, pp. 47-69.

[19] Ramakrishnan, V. and Lokvik, B. J., "Fatigue Strength and Endurance Limit of Plain and Fiber Reinforced Concretes-A Critical Review," Proceedings of the International Symposium on Fatigue and Fracture in Steel and Concrete Structures, Madras, India, Dec 19-21, 1991, A. A. Balkema, Rotterdam, 1992, pp. 381-407.

[20] Hsu, T. T. C., "Fatigue of Plain Concrete," ACI J., Vol. 78, No. 4, 1981, pp. 292-305.

[21] Tepfers, R., "Tensile Fatigue Strength of Plain Concrete," ACI J., Vol. 76, No. 8, 1979, pp. 919-933.

[22] Oh, B. H., "Fatigue Analysis of Plain Concrete in Flexure," J. Struct. Eng., Vol. 112, No. 2, 1986, pp. 273-288.

[23] Oh, B. H., "Fatigue-Life Distribution of Concrete for Various Stress Levels," Mater. J., Vol. 88, No. 2, 1991, pp. 122-128.

[24] Olsson, K. and Pettersson, J., 2010, "Fatigue Assessment Methods for Reinforced Concrete Bridges in Eurocode: Comparative Study of Design Methods of Railway Bridges," M.S. thesis, Chalmers University of Technology, Goteborg, Sweden.

[25] Aggelis, D. G., "Classification of Cracking Mode in Concrete by Acoustic Emission Parameters," Mech. Res. Commun., Vol. 38, No. 3, 2011, pp. 153-157.

[26] Ohno, K. and Ohtsu, M., "Crack Classification in Concrete Based on Acoustic Emission," Constr. Build. Mater., Vol. 24, No. 12, 2010, pp. 2339-2346.

[27] Grosse, C. U. and Ohtsu, M., Acoustic Emission Testing, Springer, New York, 2008.

[28] Ternwchek, S. J., "Acoustic Emission and Ultrasonic Testing for Mechanical Integrity," Acoustic Emission: Standards and Technology Update, ASTM STP 1353, S. J. Vahaviolos, Ed., ASTM International, West Conshohocken, PA, 1999, pp. 79-92.

[29] Vidya Sagar, R. and Raghu Prasad, B. K., "A Review of Recent Development in Parametric Based Acoustic Emission Techniques Applied to Concrete Structures," Nondestruct. Test Eval., Vol. 27, No. 1, 2010, pp. 47-68.

[30] RILEM TC 212-ACD, "Acoustic Emission and Related NDE Techniques for Crack Detection and Damage Evaluation in Concrete. Measurement Method for Acoustic Emission Signals in Concrete," Mater. Struct., Vol. 43, No. 9, 2010, pp. 1177-1181.

[31] RILEM TC 212-ACD, "Acoustic Emission and Related NDE Techniques for Crack Detection and Damage Evaluation in Concrete. Test Method for Damage Qualification of Reinforced Concrete Beams by AE," Mater. Struct., Vol. 43, No. 9, 2010, pp. 1183-1186.

[32] RILEM TC 212-ACD, "Acoustic Emission and Related NDE Techniques for Crack Detection and Damage Evaluation in Concrete. Test Method for Classification of Active Cracks in Concrete Structures by Acoustic Emission," Mater. Struct., Vol. 43, No. 9, 2010, pp. 1187-1189.

[33] Gutenberg, B. and Richter, C. F., "Frequency of Earthquakes in California," Bull. Seism. Soc. Am., Vol. 34, No. \#, 1944, pp. 185-188.
[34] Mogi, K., "Magnitude-Frequency Relation for Elastic Shocks Accompanying Fracture of Various Materials and Some Related Problems in Earthquakes," Bull. Earth. Res. Inst. Vol. 40, 1965, pp. 831-853.

[35] Richter, C. F., Elementary Seismology, W. H. Freeman and Company, London, 1958.

[36] Smith, W., "Evidence for Precursory Changes in the Frequency-Magnitude b-Value," Geophys. J. R. Astron. Soc., Vol. 86, No. 3, 1986, pp. 815-838.

[37] Scholz, C. H., "The Frequency-Magnitude Relation of Microfracturing in Rock and its Relation to Earthquakes," Bull. Seismol. Soc. Am., Vol. 58, No. 1, 1968, pp. 399-415.

[38] Wyss, M., "Towards a Physical Understanding of the Earthquake Frequency Distribution," Geophys. J. R. Astron. Soc., Vol. 31, No. 4, 1973, pp. 341-359.

[39] Fielder, G., "Local $b$-Values Related to Seismicity," Tectonophysics, Vol. 23, No. 3, 1974, pp. 277-282.

[40] Rao, M. V. M. S. and Lakshmi, K. J. P., "Analysis of $b$ Value and Improved $b$-Value of Acoustic Emissions Accompanying Rock Fracture," Curr. Sci., Vol. 89, No. 9, 2005, pp. 1577-1582.

[41] Colombo, S., Main, I. G., and Forde, M. C., "Assessing Damage of Reinforced Concrete Beam Using $b$-Value Analysis of Acoustic Emission Signals," J. Mater. Civ. Eng., Vol. 15, No. 3, 2003, pp. 280-286.

[42] Farhidzadeh, A., Salamone, S., Luna, B., and Whittaker, A., "Acoustic Emission Monitoring of a Reinforced Concrete Shear Wall by $b$-Value Based Outlier Analysis," Struct. Health Monit., Vol. 12, No. 1, 2013, pp. 3-13.

[43] Farhidzadeh, A., Dehghan-Niri, E., Salamone, S., Luna, B., and Whittaker, A., "Monitoring Crack Propagation in Reinforced Concrete Shear Walls by Acoustic Emission," J. Struct. Eng., Vol. 139, No. 12, 2013, p. 04013010.

[44] Kurz, J. H., Finck, F., Grosse, C. U., and Reinhardt, H. W., "Stress Drop and Stress Redistribution in Concrete Quantified Over Time by the $b$-Value Analysis," Struct. Health Monit., Vol. 5, No. 1, 2006, pp. 69-81.

[45] Schumacher, T., Higgins, C., and Lovejoy, S., "Estimating Operating Load Conditions on Reinforced Concrete Highway Bridges With $b$-Value Analysis From Acoustic Emission Monitoring," Struct. Health Monit., Vol. 10, No. 1, 2011, pp. 17-32.

[46] Carpinteri, A., Lacidogna, G., and Puzzi, S., "From Criticality to Final Collapse: Evolution of $b$-Value 1.5 to 1.0," Chaos Solitons Fract., Vol. 41, No. 2, 2009, pp. 843-853.

[47] Nielsen, J. and Griffin, D. F., "Acoustic Emission of Plain Concrete," J. Test Eval., Vol. 5, No. 6, 1977, pp. 476-483.

[48] Shiotani, T., Yuyuma, S., Li, Z., and Ohtsu, M., "Application of AE Improved $b$-Value to Quantitative Evaluation of Fracture Process in Concrete Materials," J. Acoust. Emis., Vol. 19, 2001, pp. 118-133.

[49] Shiotani, T., Fujii, K., Aoki, T., and Amou, K., "Evaluation of Progressive Failure Using AE Sources and Improved $b$ Value on Slope Model Tests," Prog. Acoust. Emiss., VII, JSNDI, 1994, pp. 529-534.

[50] Shiotani, T., Yuyama, S., Li, Z. W., and Ohtsu, M., "Quantitative Evaluation of Fracture Process in Concrete by the Use of Improved $b$-Value," Proceedings of the 5th International Symposium on Non-Destructive Testing in Civil Engineering, Hong Kong, China, December 10-15, 
2000, T. Uohoto, Ed., Elsevier Science, Amsterdam, pp. 293-302.

[51] Vidya Sagar, R. and Rao, M. V. M. S., “An Experimental Study on Loading Rate Effect on Acoustic Emission Based $b$-Values Related to Reinforced Concrete Fracture," Constr. Build. Mater., Vol. 70, 2014, pp. 460-472.

[52] IS 456, Indian Standard Code of Practice for Plain and Reinforced Concrete, Fourth Revision, Bureau of Indian Standards, New Delhi, India, 2002.

[53] Cox, S. J. D. and Meridith, P. G., "Micro-Cracking Formation and Material Softening in Rock Measured by
Monitoring Acoustic Emissions," Int. J. Rock Mech. Min. Sci. Geomech. Abs., Vol. 30, No. 1, 1983, pp. 11-24.

[54] Hatton, C. G., Main, I. G., and Meredith, P. G., "A Comparison of Seismic and Structural Measurements of Scaling Exponents During Tensile Sub-Critical Crack Growth," J. Struct. Geol., Vol. 15, No. 12, 1993, pp. 1485-1495.

[55] Main, I. G., Meredith, P. G., and Jones, C., "A Reinterpretation of the Precursory Seismic b-Value Anomaly From Fracture Mechanics," Geophys. J., Vol. 96, No. 1, 1989, pp. 131-138. 